\title{
Dos guetos que habito: negritudes em procedimentos poéticos cênicos
}

On the guettos I live in: Negro Identities in poetic stage procedures

Adriana Patricia Santos ${ }^{1}$

Stephan Arnulf Baumgärtel 2 


\section{Resumo}

As construções identitárias são territórios dinâmicos, ambivalentes e de negociação. Nesse sentido, falar de negritude parte do reconhecimento de que se age em determinado contexto. Um dos desafios para atores/performers negros seria como superar uma noção essencialista de negritude para uma noção performativa em que a negritude opere enquanto dispositivo para uma poética? A reflexão a seguir discorre sobre como evidenciar os riscos dos discursos coloniais e pós-coloniais na cena para propor uma reflexividade com o que está apenas provisoriamente fixado enquanto identidade. Discutimos essa potencialidade a partir da noção de dispositivos cênicos provocadores.

Palavras-chave: Negritude; subjetividade; identidade; poética teatral negra e performance.

\section{Abstract}

Identity constructions are dynamic, ambivalents and negotiations territories. Therefore, speaking of blackness starts with the recognition that one always acts in a certain context and from a specific point of view. One of the challenges for black actors and black performers would be how to overcome an essentialist notion of blackness and work with a performative notion through which blackness operates as a poetic device. The following reflection discusses how to highlight the risks of colonial and postcolonial discourses on stage in order to propose reflexivity on what is only provisionally fixed as identity. We discuss this potential through the notion of provocative theatrical devices.

Keywords: Blackness; subjectivity; identity; black and poetic theatrical performance.
ISSN: 1414.5731

E-ISSN: 2358.6958

\footnotetext{
${ }^{1}$ Atriz, Palhaça, Pesquisadora e Professora colaboradora no Departamento de Artes Cênicas da UDESC. Doutoranda em Teatro pelo PPGT/UDESC adripsantos10@gmail.com

2 Prof. Dr. Associado da Universidade do Estado de Santa Catarina (UDESC), atuando junto ao Programa de Pós-Graduação em Teatro (PPGT-CEART). stephao08@yahoo.com.br
} 
Inquirido sobre a sua raça, respondeu:

- A minha raça sou eu, João Passarinheiro.

Convidado a explicar-se, acrescentou:

- Minha raça sou eu mesmo. A pessoa é uma humanidade individual.

Cada homem é uma raça, senhor polícia.

[Mia Couto em Cada homem é uma raça - Contos]

A frase do conto de Mia Couto nos suscita a problemática identitária e subjetiva do "eu". Diferente da sugestão de um "Eu" em letra maiúscula, que se colocaria como estrutura fechada em si, autônoma e auto-poética conforme o pensamento cartesiano ocidental, esta proposição nos carrega para a noção de um eu-diluído, um eu-todo e (talvez simultaneamente) um eu-metonímico, um ser singular, mas de modo algum um ser individual.

Em muitas tradições africanas a noção do "eu" equivale ao "nós"; eu e nós não são noções dualistas; a identidade do "Eu" não existe. A identidade é múltipla e, portanto, nós ${ }^{3}$. Com essa reflexão, Toumani Kouyaté ${ }^{4}$ suscita-nos a pensar que abordar o jogo das identidades sob esta perspectiva nos coloca numa responsabilidade reflexiva e crítica de alteridade, na medida em que nos demanda a consciência de nossa coletividade para chegar em uma noção de quem somos, o que não somos, o que não podemos ser, e a partir dessa perspectiva perceber como estamos "sendo" e agindo no todo, e continuar a agir na sociedade tendo em vista este pertencimento.

Para um ponto de vista eurocêntrico, essa abordagem múltipla e construtivista sobre a questão da identidade está presente nos aportes teóricos pós-modernos e legitimada como um paradigma de identidade que problematiza uma visão cartesiana de sujeito. No entanto, essa abordagem integral sobre o modo de ver os seres humanos e sua relação com o social faz parte de um saber ancestral de muitos povos africanos, antes mesmo da revolução paradigmática do sujeito tal como proposto por Descartes 5 .

\footnotetext{
${ }^{3} \mathrm{Na}$ conferência "Povo Mandinga: sociedades de tradições orais e sistemas Pedagógicos", a qual estive presente, um dos pensamentos compartilhados foi sobre a noção de alteridade "eu e nós" no saber pedagógico da África do oeste. A palestra fez parte de uma das ações do Núcleo de Estudos Afro -Brasileiros (NEAB/UDESC) no ano de 2015, integrante do Ciclo de Palestras intitulado "Africanidades, Cultura e Cidadania" e foi ministrada por Toumani Kouyaté. (Ver: http://www.abpn.org.br/neabs/index.php?title=NEAB/UDESC. Catálogos dos Núcleos de estudos brasileiros- NEABS)

4 Toumani Kouyaté faz parte de uma linha de Djélis - griots da África do Oeste. Mestre da palavra e das artes na África do Oeste, os Djélis desempenham um papel vital na coesão social e conduzem sempre as grandes cerimônias tradicionais. São portadores das árvores genealógicas dos povos do Mandé, são depositários e protetores dos costumes e dos ritos malinkés. Eles são a biblioteca dos povos malinké. São conselheiros, mediadores, psicólogos, filósofos, poetas, contadores de histórias, músicos, dançarinos, cantores, atores. Eles são considerados artistas complexos e completos. Como todos da casta dos Djélis, Toumani canta, dança, toca, conta histórias e é também fotografo, professor universitário e organizador de festivais em vários lugares da África, América, Ásia e Europa, entre outros.(Ver: https://dinahfeldman.wordpress. com/toumani-kouyate-no-brasil. Acesso: 17/04/2015)

${ }^{5}$ Essa afirmação é feita com base nos estímulos dos Estudos Africana, abordagem epistemológica de um novo campo de conhecimento na academia dos E.U.A. e que foi fruto das lutas políticas protagonizadas por intelectuais ativistas afrodescendentes a partir da década de 1960 como crítica a visão eurocên-
}

trica e analítica existente nas teorias que discursam sobre os povos africanos e de diáspora. 0 termo "Estudos Africana" não é referido como o feminino de africano; é usado de forma plural em latim para indicar a múltipla abrangência do campo, que estuda os povos africanos e afrodescendentes em todo o mundo (Nascimento, 2009, p. 29) Este campo propõe uma perspectiva afrocêntrica na construção do conhecimento. A afrocentricidade, como vem sendo designado o termo, é um tipo de pensamento, pratica e perspectiva que percebe os africanos como agenciadores de suas produções culturais e intelectuais. "O diálogo com a cultura africana requer que os profissionais dos Estudos Africana coloquem em cada encruzilhada crítica na pesquisa, no escrever e no discurso, a questão crucial: o que os povos africanos e a cultura africana tem a oferecer aos esforços em direção à compreensão e a melhoria da condição humana e ao enriquecimento do prospecto humano" (Karenga, 2009, p. 349). É neste sentido que considero importante realizar o esforço de apoiar-se em outras perspectivas filosóficas para pensar a negritude, sociedade e teatro. "Se não gerar conceitos de forma consciente, o campo dos estudos Africana será apenas um gueto acadêmico, ou seja, um lugar em que os africanos viverão em estado de pobreza intelectual, as margens da academia ocidental e ávidos por aceitar as interpretações prevalecentes elaboradas por pensadores brancos". (Rabaka, 2009, p. 134). Nesse sentido que, trazer nesta ocasião a contribuição do pensamento africano sobre sujeito, pautado num paradigma não cartesiano antes mesmo da visão moderna, nos mostra o quanto ainda há que se (des) construir na práxis a noção de sujeito sob uma perspectiva eurocêntrica, ainda que na teoria habitemos um paradigma pós-moderno. 
Falar de negritude no Brasil implica reconhecer-se e agir em determinado contexto diaspórico, neste eu-metonímico. As construções identitárias são territórios dinâmicos, ambivalentes e de negociação. Kabengele Munanga, um dos estudiosos da cultura negra no Brasil desenvolveu em seu livro Negritude: Uso e sentidos uma reflexão sobre os significados de negritude: ela é designada pela cor da pele e pelo corpo unicamente ou pela cultura e pela consciência do oprimido?

Munanga (2012, p.57) discorre que enquanto conceito e movimento ideológico a negritude nasceu há cerca de 70 anos e percorrendo a história do conceito pode-se dizer que as diversas acepções da negritude oscilam entre duas interpretações antinômicas: uma mítica e outra ideológica. A primeira se refere à descoberta do passado africano anterior à colonização e uma explicação de mundo, almejando um retorno às origens, para revitalizar a realidade africana perturbada pela intervenção ocidental. A segunda propõe esquemas de ação, um conjunto de comportamentos, atitudes e modos de agir que constituem o que vem a ser compreendido como 'ser negro'. Trata-se de um conjunto de ações que pode ser interpretada como resposta às situações históricas comuns aos negros colonizados. Neste sentido, o desafio dos afrodescendentes da diáspora brasileira de traçar um "pertencimento", de realizar a Sankofa ${ }^{6}$, é uma árdua tarefa devido aos riscos da definição de identidade sob um ponto de vista essencialista, ao invés de um olhar construtivista e performativo de si mesmo.

Dentro da acepção ideológica de negritude temos a égide sociocultural de classe e de raça, que a coloca como conceito operacional para descrever posições sociais de pessoas negras de um ponto de vista tanto pessoal (modos de sentir e pensar) quanto coletivo (suas posições objetivas na hierarquia socioeconômica). Essa abordagem sobre a negritude é vinculada com um construtivismo social que relaciona as categorias de classe e de raça, mas adverte em não se ater à visão puramente socioeconômica de classe, uma vez que esta visão classista pode funcionar como modo de mascarar ideologicamente um mecanismo específico de opressão. Portanto, esse olhar sobre a negritude defende que o mundo negro no seu conjunto vive uma situação específica, sofrendo discriminação baseada na cor, ainda que a discriminação por classe exista.

Outra vertente oscila entre uma acepção mítica e ideológico- construtivista de negritude, pois suscita elementos de subjetividade; seria a definição psicológica em que o conceito de negritude seria composto por um conjunto de traços característicos inerentes ao ser negro no que se refere a seu comportamento, sua capacidade de emoção, sua personalidade. (Munanga, 2012, p. 58).

No contexto deste trabalho, compreendo a noção de negritude como estritamente ligada à fatores políticos e/ou negociações de raça e de identidade. Se raça e

\footnotetext{
${ }^{6}$ Sankofa é um dos adinkra, conjunto de ideogramas que compõem a escrita dos povos akan, da África Ocidental, em especial os asante da atual república do Gana. Significa se wo were fi na wo sankofa a yenkyi "nunca é tarde para voltar e recolher o que ficou pra trás"; símbolo da sabedoria de aprender com o passado para construir o futuro (Nascimento, 2009, p. 28)
} 
identidade não são elaborações fixas e são produtos de fatores sociais e, portanto, cultural e socialmente construídos, falar de negritude é assumir a performatividade ${ }^{7}$ inerente a sua própria definição. Este argumento será elaborado no decorrer deste artigo e propulsiona esta reflexão.

O professor Harry J. Elam Jr8 $(2001$, p. 4) ao falar do Teatro Negro nos Estados Unidos, afirma que a questão da raça é inerentemente teatral, pois ela em si é imbuída de teatralidade, já que depende fundamentalmente da relação entre ver e ser visto; entre visivelmente marcado e não marcado, entre o real e a ilusão.

Afirma ainda que, se as noções de raça e identidade são tidas, recentemente, como construções determinadas socioculturalmente e historicamente, seus discursos continuam tendo significados e efeitos empíricos, ou seja, definições de raça e identidade podem ter significados artificiais e até ilusórios, mas não por isso deixam de ter consequências empíricas concretas condizentes com esses significados socialmente criados. Os conceitos promovem certas práticas que, por sua vez, estabilizam e até fixam os conceitos identitários. Por isso, o desejo de subverter "as políticas de representação" hegemônicas, termo este definido por Stuart Hall (2003), e de controlar políticas de representação de resistência tem desempenhado um importante papel na história do teatro e da performance negra nos EUA.

Elam (2001, p. 6) narra que praticantes de um teatro negro se preocupam com a viabilidade deste teatro como um protesto social. Podemos entender, então, a questão da negritude como construção discursiva, o que não significa afirmar que o racismo e suas bases de um pensamento essencialista não existam. Vemos o conceito de negritude, nesse contexto, como uma construção sociocultural que permite justificar ações anti-essencialistas com objetivos anti-racistas concretos. Como conceito, a negritude é marcada pela a ambivalência de não ser nada em si mesmo, e ao mesmo tempo de causar efeitos que retroativamente lhe atribuem certa materialidade concreta.

Em se tratando do contexto brasileiro e baseando-se em dados advindos de pesquisa realizada sobre atores e atrizes negras no teatro brasileiro (TB), percebese que a experiência negra no TB converge com as constatações do professor Elam Jr.(2001). A luta por uma emancipação do negro através do teatro se deu e se dá em

\footnotetext{
7 As noções de performance, performatividade e performer que permeiam esta reflexão são pautadas nos pressupostos de Richard Schechner (2002), sobretudo no que diz respeito a sua diferenciação entre "fazer" e "mostrar o fazer" como dois aspectos da performatividade em cena. Entendo aqui que 0 'fazer' se manifesta cenicamente em ações que não necessitam representar uma figura ficcional anterior à apresentação, mas obviamente podem levar à construção dessa figura na imaginação do espectador. 0 que importa, e aqui entra a noção da construção performativa de identidades de gênero proposta por Judith Butler (2003), é o espectador perceber esse 'fazer', ou seja, que ele seja abertamente mostrado em cena, e assim, constitui uma construção performativa de uma noção como 'negritude'. ,Nesse sentido, o termo performatividade remete aqui menos à prática da performance art, mas a um modo de apresentar cenicamente um corpo, sua corporeidade/materialidade e sua dimensão semântica. Dessa maneira, o termo permite cruzar meu interesse cênico com um interesse de origem antropológico e social.

8 HARRY J. ELAM JR. é Professor de ciências humanas, diretor de estudos de pós-graduação em Drama, e presidente da comissão de Performance e arte negra na Universidade de Stanford, EUA.
} 
diferentes aspectos, porém com este fator comum que é problematizar e/ou evidenciar as políticas de representação com relação às questões raciais e identitárias ${ }^{9}$.

Se o problema da negritude é provido desta "dinâmica teatral", ela é também diretamente associada à noção de mímica. Homi K. Bhabha se apoia na ideia de mímica para fundamentar o conceito de ambivalência do discurso colonial: "a ameaça da mímica é sua visão dupla que, ao revelar a ambivalência do discurso colonial, também desestabiliza sua autoridade" (Bhabha, 1998, p. 133). Para ele, esta ambivalência é inerente ao projeto mimético colonial, uma vez que deste emerge um sujeito com presença parcial, incompleto e virtual. A mímica é uma estratégia de repetição e proliferação deste discurso colonial, e ao mesmo tempo faz ressaltar a diferença; ao mesmo tempo em que busca fixar estereótipos identitários, ela é uma ameaça a este projeto, na medida em que, expõe a fragilidade, o medo do Outro e faz emergir o que está ausente, o que falta:

Na mímica, a representação da identidade e do sentido é rearticulada ao longo do eixo da metonímia. Como lembra Lacan, a mímica é como camuflagem, não uma harmonização ou repressão da diferença, mas uma forma de semelhança que difere da presença e a defende, expondo-a em parte, metonimicamente. Sua ameaça vem da prodigiosa e estratégica produção de "efeitos de identidade" conflituosos, fantásticos e discriminatórios, no jogo de um poder que é elusivo, porque não esconde nenhuma essência, nenhum "si-próprio" (Bhabha, 1998, p. 135).

Performar a negritude no teatro é reconhecer-se em meio às forças deste projeto mimético sociocultural e histórico, cuja noção de sujeito se dá pela ordem de uma presença parcial, incompleta e virtual; é reconhecer-se no que é parcial, no que falta, e ao mesmo tempo não emaranhar-se nos próprios projetos estereotipados de raça e identidade; é reconhecer-se como produto desta ambivalência. Não se trata de uma tentativa de apresentar ou constituir uma 'presença' do ser negro; de estabelecer a negritude como 'presença' no sentido enfático da palavra. Esse projeto de construção de uma presença plena remeteria inevitavelmente a um contexto essencialista, o que foge da fundamentação crítica de minha argumentação.

Neste sentido, apropriando-me da reflexão de Elam Jr, a produção da/o performer negro/a constitui-se numa negociação com essa ambivalência nos diferentes âmbitos relacionais: subjetivo, real e/ou empírico e discursivo.

A/O performer negro/a visto/a e/ou lido/a pelo público como negro/a, entra no palco e negocia não só com os espaços entre a representação no palco e a realidade social, mas também com as definições, equívocos e estereótipos raciais, e

9 Em estudo realizado no mestrado estudei práticas de atores e atrizes negros
em diferentes grupos no país. Os atores e atrizes que contribuíram para a
pesquisa são de grupos que trabalham politicamente com a temática sobre
o negro (muitos com integrantes somente negros) e de grupos que não têm
suas práticas focadas nessa temática, mas que possuem atores negros em
seu coletivo. A partir deste estudo foi constatada a existência de cinco modali-
dades de luta com relação à problemática do negro na cena teatral brasileira:
1- Valorização da cultura negra e exaltação das diversas manifestações cul-
turais de origem africana e afro-brasileira; 2 - Representação de histórias de
grandes personalidades negras nas histórias africanas e/ou brasileiras, bem
como episódios de realidade histórica ocorrida desde os primórdios até então, cujas tramas tratam do sofrimento e superação da escravidão, até as realidades em favelas e periferias sociais brasileiras; 3 - Discursos de militância evidente na enunciação: política de denúncia da situação social do negro e 0 racismo; 4 - Valorização de dramaturgia de escritores negros: personagens negros como protagonistas; 5 - Rompimento de paradigmas de preconceito através da própria presença do ator/atriz negra em situações cênicas diversas: demonstração da qualidade profissional tão quanto o branco. Dos grupos estudados alguns articulavam entre si essas modalidades, outros focavam mais em uma que outra em suas produções artísticas. Diante dessas modalidades percebe-se que cada qual opera (ou pelo menos pretende operar) numa camada de passível transformação do outro. 
a ambivalências de raça. O/A perfomer negro/a pode propositalmente reconhecer e utilizar seu status ambíguo, como pessoa real, como uma representação teatral e como construção sociocultural expondo o controle de representação racial; expor, explorar e explodir essas definições a partir de provocação e ressignificação de discursos.

Diante disso um dos desafios para atores/performers negros seria como operar nessa ambivalência? Como oscilar de uma noção essencialista de negritude para uma noção performativa em que a negritude opere enquanto dispositivo para uma poética, mas um dispositivo abertamente teatralizado e nisso exposto ao olhar crítico? Dos guetos ${ }^{10}$ que habito: quem demarcou? Quais os limites e estigmas destes guetos? Em que medidas esses guetos são prisão, refúgio, subordinação ou estratégia de sobrevivência?

Em busca de possíveis respostas, apresento a seguir alguns procedimentos poéticos cênicos (PPC) que, a meu ver, expõem essa ambivalência, e que evidenciam os atravessamentos discursivos com relação à negritude. Trata-se do processo de pesquisa que vem sendo realizado no meu doutorado e cuja proposta é produzir dispositivos cênicos que irão gerar performance/palestra e ao mesmo tempo a teoria.

\section{Procedimento Poético Cênico 1 - Dispositivo "drag quem?"}

A residência ${ }^{11}$ Hackers de gênero, ministrada por Clara Lee Lundberg ${ }^{12}$ promovida pelo Vértice Brasil - encontro de teatro feito por mulheres, realizada em julho de 2014 na qual fui participante, proporcionou aproximações com as propostas das teorias queer que tem como uma das principais porta-vozes Beatriz Preciado ${ }^{13}$. Foram

10 O termo gueto suscitou polêmicos debates e carrega sentido ambíguo em suas tentativas de definição. Este conceito é evocado na ocasião por dialogar diretamente com o dilema que enfrentamos ao falar de políticas de identidade, sendo assim para pensar estas questões enquanto atriz e pesquisadora no teatro refiro-me ao termo no plural para justamente repensar este lugar através da prática cênica. Não cabe no momento aprofundar a etimologia e implicações deste conceito, porém interessa nos ater que apesar das diferentes acepções sobre este termo, "pode-se extrair dessas diferentes literaturas algumas semelhanças e propriedades recorrentes na construção de um conceito relacional de gueto como um instrumento de cercamento e controle, o que esclarece grande parte da confusão que o circunda e faz dele um instrumento poderoso de análise social da dominação étnico-racial e da desigualdade urbana. $O$ termo gueto, além de uma denominação física, passou também a representar uma atitude mental que se estendeu aos judeus de outras terras, à medida que as condições de gueto passaram a se estender para além da Itália e da Alemanha, a outras partes da Europa. Fazia com que os judeus fossem considerados proscritos sociais. Podem ser detectados nesse momento inaugural os quatro elementos que constituem o gueto, isto é, o estigma, o limite, o confinamento espacial e o encapsulamento institucional. 0 gueto é um meio sócio organizacional que usa o espaço com o fim de conciliar dois objetivos antinômicos: maximizar os lucros materiais extraídos de um grupo visto como pervertido e perversor e minimizar o contato íntimo com seus membros, a fim de evitar a ameaça de corrosão simbólica e de contágio. 0 gueto é o produto de uma dialética móvel e tensa entre a hostilidade externa e a afinidade interna que se expressa como uma ambivalência no nível do consciente coletivo. Primeiramente, o gueto reafirma o limite entre a categoria marginalizada e a população que a circunda, uma vez que intensifica o abismo sócio-cultural entre elas: ele faz que seus residentes sejam objetiva e subjetivamente diferentes de outros residentes urbanos ao submetê-los a condições únicas, de maneira que os padrões de cognição e conduta sejam compreendidos como singulares, exóticos ou até aberrantes. A dupla face do gueto como arma e escudo implica que, na medida em que sua completude institucional e autonomia minguam, seu papel protetor para o grupo subordinado diminui, restando somente a força de sua função exclusivista. (Wacquant, 2004, pág. 157-162).

11 Sobre a proposta da residência, a ministrante Clara Lee Lundberng afirma que: "Nesta residência vamos nos transformar em "hackers de gênero" e explorar a potencialidade do corpo político! Com enfoque na experimentação performática de gênero, iremos pesquisar e desafiar as expressões "feminilidade" e "masculinidade" e criar um espaço crítico de reflexão e ação. Tomando como base teórica o livro "Testo Yonki" de Beatriz Preciado, que aborda a temática queer, gênero, performatividade e transgender, a residência propõe trabalhar com dispositivos como técnicas de dragking /dragqueen, radical contact improvisation, pornografia feminista, crossdressing, luta, boxe e improvisações de atuação e movimento. Também serão propostas discussões teóricas e ações cênicas, com o intuito de desconstruir "verdades" sobre nossos corpos "femininos", permitindo a possibilidade de transitar por novos estados corporais e psicológicos, extrapolando os gêneros socialmente estabelecidos". ${ }^{12}$ Clara Lee Lundberg (Suécia) é artista multidisciplinar, coreógrafa e bailarina, residente no Rio de Janeiro. Tem interesse em pesquisar as relações sócio-políticas, estruturas neocoloniais, teorias queer, normas estéticas e produção de teorias filosóficas. Seu trabalho está influenciado por filósofos e pensadores como Jean-Luc Nancy, Gayatri Spivak, Frantz Fanon, Beatriz Preciado e Michel Foucault.

13 Filósofa contemporânea, conhecida por ser uma das maiores representantes das teorias queer que, junto com Judith Butler dão continuidade aos pensamentos de Foucault, Derridá e Deleuze. 
dias de intensas práticas cujo enfoque foram questões de gênero e experimentação de procedimento poético denominado "dispositivo drag king" e "dispositivo dragqueen" termos estes serão desenvolvidos mais adiante.

O interesse sobre a perspectiva teórica queer se dá pelo fato de se tratar de uma teoria e de uma política pós-identitária, como afirmam alguns estudiosos desta vertente no Brasil e que trabalha sobre a noção da ambivalência dos discursos. Ao apropriar de uma palavra que é um julgamento, um insulto estereotipado advindo do fluxo discursivo heteronormativo, o termo em si provoca a manifestação desestabilizadora da diferença no interior do fenômeno do gênero. Guacira Lopes Louro ${ }^{14}$ discorre que o termo faz eclodir o que está em emergência, tanto no sentido emergencial quanto no que está por emergir:

Queer pode ser traduzido por estranho, talvez ridículo, excêntrico, raro, extraordinário. Mas a expressão também se constitui na forma pejorativa com que são designados homens e mulheres homossexuais. Um insulto que tem, para usar o argumento de Judith Butler, a força de uma invocação sempre repetida, um insulto que ecoa e reitera os gritos de muitos grupos homófobos, ao longo do tempo, e que, por isso, adquire força, conferindo um lugar discriminado e abjeto àqueles a quem é dirigido. Este termo, com toda sua carga de estranheza e de deboche é assumido por uma vertente dos movimentos homossexuais precisamente para caracterizar sua perspectiva de oposição e de contestação. (Louro, 2001, p. 546).

Ou seja, queer implica em colocar-se contra a normatização presente em diversos níveis nas negociações e políticas de gênero. "Queer seria a diferença que não quer ser assimilada ou tolerada" (Louro, 2001, p. 546). Compartilho com esta perspectiva as questões acerca do termo negritude; pois esta postura pode responder ao desafio lançado anteriormente neste artigo: como oscilar de uma noção essencialista de negritude para uma noção performativa em que a negritude opere enquanto dispositivo potencializador para uma poética desestabilizadora dessa noção.

Conforme mencionado acima, na residência trabalhamos os procedimentos intitulados "dispositivos drag-king" e "dispositivos drag-queen" seriam dispositivos que se usam para quebrar a programação e/ou clichês. Trata-se de um procedimento cênico que busca experimentar através da performação do outro; não como personagens, mas como figurações do que seriam o masculino e o feminino enquanto construções socioculturais e, consequentemente, ampliar e evidenciar o que emerge enquanto discurso normativo em questões de gênero.

Cada participante criou uma figura masculina e outra feminina e partir de sua ação com o contexto (outras/os participantes, a sala, o local onde foi realizada a residência, outras/os espectadores do local e da rua) e experimentou na cena o jogo das negociações identitárias de gênero, surpreendendo-se com o próprio julgamento e padrões de si mesmo como também provocando o olhar de quem vê. Desta maneira, os participantes podiam problematizar os diversos níveis de atravessamento repre14 Licenciada em História pela Universidade Federal do Rio Grande do Sul
(1969), Mestre em Educação pela Universidade Federal do Rio Grande do
Sul (1976) e Doutora em Educação pela Universidade Estadual de Campi-
nas (1986). Professora Titular aposentada da Universidade Federal do Rio
Grande do Sul. Foi fundadora do GEERGE (Grupo de Estudos de Educação e Relações de Gênero) e participa deste grupo de pesquisa desde 1990. Tem publicado livros, artigos e capitulos, bem como orientado dissertações e teses sobre questões de gênero, sexualidade e teoria queer em articulação com 0 campo da Educação. Suas pesquisas atuais voltam-se para estudos queer, cinema e pedagogias da sexualidade. 
sentacional (discursivo, subjetivo, empírico) para uma noção performática do gênero.

A nível discursivo, pois foi nos solicitada a tarefa de construir um caráter (um personagem) com o que seriam referentes masculinos para cada participante/pesquisadora, fato este que nos demanda uma busca um tanto racional e lógica de representação (estereótipos comportamentais, etc). A nível subjetivo pois nesta escolha do caráter a ser experimentado, os referentes que acionamos para a concepção desta figura masculina são os diversos tipos de homens de nossa convivência pessoal, o que consequentemente, suscitam fatores subjetivos e psicológicos. E por ultimo, a nível empírico, pois no ato da apresentação deste caráter masculino, ou seja, ao performá-lo em cena e a agir e/ou reagir conforme o contexto apresentado no momento, ampliou-nos o olhar sobre a noção de gênero e detecção de códigos comportamentais estabelecidos socialmente, para então vislumbrar as possibilidades de desconstruções destes códigos.

Inspirando-se neste procedimento cênico elaborei o chamado dispositivo "drag quem?", no intuito de transportar esse modus operandi para questões em torno da negritude e branquitude ${ }^{15}$.

Sendo assim, o "dispositivo drag-quem?" pretende, a partir da experimentação figurativa de performar o outro, evidenciar discursos normativos do que é 'ser branco' e 'ser negro' em nosso contexto e com isso provocar tanto a mim mesma, enquanto atriz/performer/negra, quanto ao olhar e percepção do outro no que tange as políticas de identidade. Este dispositivo enquanto cena performática subverte os padrões de significação na cena oscilando entre consciência de identificação destes padrões e ao mesmo tempo o rompimento destes.

Tais como descrito acima sobre os atravessamentos a nível discursivo, subjetivo e empírico na práxis dos dispositivos drag king; na perspectiva do dispositivo drag quem? a proposta está sendo criar caráteres (personagens) oriundos de meu olhar sobre o que seria negros e brancos, figuras estas que consequentemente, serão referentes de minha convivência pessoal, e performá-lo em cena, em diálogo com o público, no intuito de detectar códigos preestabelecidos e as possibilidades de revisão de estereótipos identitários.

\section{Procedimento Poético Cênico 2 - Museificação de si}

O segundo procedimento poético cênico em processo e que, a meu ver, dialoga nesta perspectiva da ambivalência em políticas de negritude foi elaborado a partir da experiência na oficina intitulada: Atuação - Tensões e processos criativos de atordiretor ministrada por Miguel Rubio Zapata, diretor do Grupo Teatral Peruano Yuyachkani ${ }^{16 .}$.

\footnotetext{
15 Este termo é designado na ocasião para se referir a padronizações e projeções identitárias relacionadas ao que seria cultura branca. A ideia é justamente contrapor ao que ethos do que seria negritude, não por mera dualidade, mas para problematizar os fluxos discursivos coloniais.

16 O Grupo Cultural Yuyachkani fundado em 1971 é uma instituição independente. Seus trabalhos, suas pedagogias e seu centro cultural estão dirigidos e relacionados com a sociedade e a diversidade cultural peruana envolvendo
}

o espectador em um ato reflexivo e não passivo. Yuyachkani renovou a cena peruana propondo um teatro inclusivo e da memória que mostra a grande diversidade peruana, encontrando justamente aí seu ponto de inspiração, tomando como referência os ritos, o sagrado, o espaço andino, entre outros, para provocar uma introspecção no passado que nos faz entender o presente (ver: http://www.yuyachkani.org/historia.html . Acesso: 20/04/2015) 
Um exemplo fundamental que permeia a prática do grupo e que serve de base para a referente pesquisa é o fato de que a trajetória do Yuyachkani é um rico parâmetro para pensar/praticar/articular questões políticas e teatro:

Rúbio pontua a mudança de rumo no campo de trabalho atorial ocorrido no Yuyachkani a partir de então. De um teatro, cujo foco estava centrado no ator-militante, ou seja, um ator que compreende criticamente seu meio social e utiliza a palavra instrumento teatral de percepção e discussão do mundo, passa à compreensão de um ator que percebe e trabalha, a partir de seus referenciais culturais, seus canais psicofísicos na construção de uma dramaturgia própria, por um procedimento de treinamento contínuo. A concepção do exercício e do oficio atorial ganha uma maior complexidade sem perder de vista se posicionamento e sua função social. (Teles, 2011, p. 145).

Neste encontro o enfoque fundamental foi pensar o ator, a memória, e seu contexto; um processo criativo que evoque um ator engajado com seu tempo, sua memória, e o diálogo entre construção da representação e desconstrução da mesma. Um jogo com o paradoxo de narrar a si mesmo, reconhecer-se e reformular possibilidades na cena. Como num tipo de esforço dialético, promover a narração em primeira pessoa (dentro de sua memória histórica) e em terceira pessoa (afastando-se dela) e nesta tensão oscilatória uma cena crítica se faria presente.

Um dos procedimentos realizados foi "a criação de seu próprio altar" de seu "museu pessoal". Lembro-me de Miguel Rubio Zapata provocando nossos pensamentos sobre a noção de museu: Qual a função do museu para determinada cultura? Que tipo de lugar é o museu? Que objetos, materiais são escolhidos para que a memória seja preservada? O que está em jogo na representação desse lugar que o museu quer guardar a memória? Memória de quem e/ou de que grupo de pessoas o museu preserva? O museu enquanto dispositivo disparador de memória, dentre outras provocações.

Após essas provocações foram trazidas, a pedido do diretor, por cada ator e atriz elementos diversos que fossem significativos e relacionais em sua memória; objetos, livros, bilhetes, etc., o que cada qual achasse fundamental para a construção de seu "próprio altar" e/ou seu "museu pessoal"; o público iria visitar esse espaço; e cada um iria ser os guia deste público ao museu. A proposta era misturar textos fictícios, histórias pessoais, oscilar a narração em primeira e segunda pessoa, nesta "apresentação" de seu próprio museu.

Particularmente, esse procedimento cênico no qual Zapata mencionou a priori de "Museificação" de si e/ou criação do seu próprio altar também coaduna com o pressuposto de refletir sobre as políticas de representação e/ou identidade. Uma espécie de iconografia simbólica de si mesmo se materializa em uma narrativa cênica e ao mesmo tempo é colocada em desconstrução narrativa, compondo uma cena fragmentada e crítica da memória social e histórica.

Este tipo de cena, ou de narrativa com relação à negritude na cena parece-me interessante, na medida em que, apoiando-se na noção de mímica de Bhabha, problematiza a mímica de um discurso colonial presente em nossa memória enquanto atores brasileiros; além de auxiliar na reflexão de como nos tornamos conscientes no exercício da sankofa: tentar apreender ao passado para compreender o presente 
e construir o futuro. A noção de museu, problematizada na forma descrita aqui, nos ajuda a pensar em evidenciar as possíveis representações essencialistas de identidade negra; estabelecendo na cena um jogo dialético entre a representação e a performação de si.

O grupo Yuyachkani defende essa noção por justamente ter enveredado, nestes mais de 40 anos de prática, no desafio que é falar de questões identitárias; de buscar trabalhar múltiplas identidades, e ao mesmo tempo não cair nos estereótipos e na visão fetichista e folclórica:

Depois de três décadas tentando assumir e sustentar essa múltipla identidade, tanto no devir histórico como nos espetáculos artísticos, como temos visto (...), a esse eterno "outro" (o elemento indígena, mestiço, serrano, ou como queiram denominar) este "Último Ensaio" [se refere ao último trabalho do grupo] parece cair numa conclusão de esta ser uma impossível tarefa. Uma das razões é sem dúvida, por ser também, já em plena era da globalização, um paradigma cultural que se desliza; uma imagem que se desvanece diante da representação cada vez mais fetichizada e camuflada por um olhar progressista oficial de caráter nacionalista, com fins pragmáticos e por assim dizer, folclorizante e até turístico ${ }^{17}$ (Rizk, 2011, p. 53).

Na passagem acima se observa mais um exemplo deste viés poético político de ambivalência com relação às identidades que o grupo Yuyachkani suscita a partir de seu espetáculo "Último ensaio".

Apropriando destes pressupostos poéticos que este PPC consiste em trabalhar a "museificação" e "construção de altar" elencando aspectos da memória tangenciados pela negritude. A proposta é promover uma práxis sobre a percepção de padrões identitários; o que está fixado e o que se move e o que pode ser desconstruído, conformando em um exercício dialético no ato cênico e um estranhamento das próprias narrativas socioculturais e históricas da atriz negra na cena.

A proposta deste PPC está em sua fase inicial. Os elementos surgidos na oficina estão em aprofundamento e processos dialógicos com referentes teóricos e práticos. A princípio alguns elementos representativos de minha vida pessoal constituem esta "cena altar" até o momento: uma boneca de pano preta; o livro "Dhammapada: pelos caminhos de Buda" da série clássicos do oriente; o livro "O ser negro: a construção de subjetividades em afro-brasileiros" de Maria Consolação Sodré; uma foto da família; uma da minha avó paterna; a imagem da minha palhaça; dois papéis, cada qual. escrito os sobrenomes de meus pais: Scarasati(mãe) e Santos(pai).

Esses elementos que compõem, a priori, meu museu pessoal, serão constitutivos da narrativa da cena na qual irei revisitar e conduzir o público em cada visita, num exercício de que para cada público, o ato de narrar a si próprio constitua-se num ato dialético e reflexivo.

\footnotetext{
17 Texto original: Después de tres decadas de intentar asumir esa múltiple identidade y darle cabida, tanto en el devenir histórico como en los espectáculos artísticos, como hemos visto [...], a ese sempiterno "otro" (el elemento indígena, cholo, serrano, o como se lo quiera denominar) este "último ensayo" [se refere ao ultimo trabalho do grupo] parece caer en el predicamento de lo imposible de la tarea. Una de las razones es, sin duda, por ser tambien, ya
}

em plena era de la globalizacion, un paradigma cultural que se desliza; una imagen que se desvanece ante la representación cada vez mas fetichizada, falseada por una mirada "progresista" oficial de caráter nacionalista aunque con fines pragmáticos, por no decir folklorizante y hasta turística . 


\section{Procedimento Poético Cênico 3 - performance e negritude}

Porque ainda tenho que dizer 'sou negra'? Esta foi uma pergunta emergida num processo de criação de uma ação de performance por mim criada e que foi impulsionada pela ordem de um manifesto pessoal realizada na disciplina Seminário Temático I: Entre o Ator e o Performer: em busca de uma especificidade epistemológica ministrada pelo professor Matteo Bonfitto no ano de 2013.

Esta experiência abriu margem para pensar os possíveis atravessamentos das políticas de negritude nas especificidades e princípios que surgem quando falamos em performance e, sobretudo, sobre a política da e/ou na performance.

A preocupação neste PPC foi pensar como elaborar uma ação em performance que evidencia o discurso e as negociações de negritude? Como abordar a questão da negritude como um dispositivo ético provocador? Ou ainda, que relação entre forma e conteúdo deve ser estabelecida para que uma ação seja potente em cena com relação à problemática sobre negro, quebra de paradigmas de preconceito, racismo, etc. Estes foram pensamentos que permearam o processo criativo da performance elaborada e ainda são motriz de minhas conjecturas.

A ação de performance surgida, a qual foi denominada de "Macaca" opera sob a mesma perspectiva de abordagem queer já mencionada, onde o insulto, o estereótipo, o clichê é tido como base de construção da própria subversão da normatividade.

$\mathrm{Na}$ ação estou de roupa preta e com máscara de gorila. Jogo com a corporeidade e movimentos de uma passista de escola de samba e a cordialidade estabelecida com o público a partir disto. Coloco a música "Requebra" do Olodum e danço buscando a virtuosidade da execução e no que me inscreve enquanto detentora deste saber corporal. O "show da macaca" vai sendo desconstruído corporalmente com as quebras do virtuosismo e criação de imagens grotescas corporais (ritmo, formas, impulsos) e a desconstrução da forma da mulata. Ao chegar numa quase exaustão, retiro a máscara rapidamente, como que se livrando de um sufocamento, e continuo a cantar a música, exatamente na parte em que diz "requebra, requebra, requebra sim! Pode falar pode ri de mim", buscando transparecer a afetação real da atriz na ação proferida. Ao acabar a música alguém do público joga uma banana de plástico (que foi dada no inicio da ação a alguém do público e acordado o momento de jogar), enquanto sorrio alegremente.

Esta breve descrição é compartilhada aqui no intuito de criar uma imagem sobre como está sendo discutida a negritude apoiada aos pressupostos performáticos e de subversão. Queria justamente testar os limites de um "querer dizer" e do "como dizer" e, sobretudo, "como afetar".

Nesse sentido que, em uma ação de performance, não há como não se apoiar em elementos de corporeidade e performatização, pois trata-se de um processo que por si procura, ou pelo menos deveria, evidenciar o tácito, o não dito, a diferença, o contra discurso. Percebe-se na arte do ator/performer o potencial para levantar tais questões identitárias de negritude fazendo jus a complexidade do material que ele mesmo disponiliza em um processo criativo, desde suas próprias corporeidades à estímulos externos com relação à temática. 
Ao refletir sobre uma estética da performance, Fischer-Lichte em seu livro The transformative power of performance argumenta que a performance escapa (ou pelo menos deveria) as exigências tradicionais do que seja a compreensão de uma obra de arte, no sentido de relação direta com o significado; entretanto, não quer dizer que o público não crie sentido. A autora afirma que pode haver na performance duas relações fundamentais: 1- A relação não dicotômica entre sujeito e objeto; observador e observado; 2- A comunhão entre materialidade e semioticidade dos elementos da performance; Na primeira a performance rompe a dicotomia convocando todos os envolvidos a serem co-sujeitos; há uma relação de oscilação entre ser observador e observado ao mesmo tempo. Na segunda a própria materialidade do corpo que cria os significados. A materialidade das ações antecipa as tentativas de interpretação do público para além da autoreferencialidade, ou seja, há uma relação entre efeito e significado. (Fischer-Lichte, 2008, p.11-23).

Nesse exercício de alteridade com nossas próprias construções identitárias, como performers de si mesmo e da cena talvez resida a potência desta ação política através da performance. A proposta é aprofundar cada vez mais a performance "Macaca" na busca destes princípios norteadores, para que se instaure a convocação do espectador como co-sujeitos da ação e para que haja mais efeito (opere pela ordem do significante) que somente geração de significados; na crença de que a problemática da negritude deslize para a exposição das fraturas de um discurso hegemônico; para que possamos ir além do "politicamente correto" nas questões de raça e identidade.

Até o momento da pesquisa estes três procedimentos poéticos cênicos acima discorridos fomentam e potencializam esta práxis de pesquisa; estes promovem na cena uma abordagem de problematização e emergência (do sentido de emergir) do mimético e do mundo da representação, neste caso, das tensões políticas de representação coloniais e diaspóricas. O material que se emerge constitui-se em dispositivos cênicos estratégicos que exponham a diferença e a normatividade dos discursos; propondo desta forma uma reflexividade e uma abordagem performática sobre a alteridade, sem abandonar o rigor específico da linguagem e da comunicação teatral.

\section{Referências}

BHABHA, Homi K. O local da cultura. Belo Horizonte: Editora UFMG, 1998.

BUTLER, Judith. Problemas de gênero: feminismo e subversão da identidade. Rio de Janeiro: Editora Civilização. Brasileira, 2003.

FISCHER-LICHTE, Érika. The transformative power of performance. In: The transformative power of performance: a new aesthetics. London. Routledge: 2008.

HALL, Stuart. Da diáspora: Identidades e mediações culturais. Org. Liv Sovik; Trad. Adelaine La Guardia Resende. Belo Horizonte: UFMG; Brasília: Representação da UNESCO no Brasil, 2003. 
KARENGA, Maulana. A função e o futuro dos estudos Africana: reflexões críticas sobre sua missão, seu significado e sua metodologia. In: Afrocentricidade: uma abordagem epistemológica inovadora. Elisa Larkin Nascimento (org.). São Paulo: Selo Negro, 2009.

LOURO, Guacira Lopes. Teoria Queer - uma política pós-identitária para a educação. Revista Estudos Feministas, v. 02, ano 09, p. 541-553, 2001.

MUNANGA, Kabengele. Negritude: usos e sentidos. Belo Horizonte: Autêntica Editora, 2012.

NASCIMENTO, Elisa Larkin (org.). Afrocentricidade: uma abordagem epistemológica inovadora. São Paulo: Selo Negro, 2009.

RABAKA, Reiland. Teoria crítica Africana. In: Afrocentricidade: uma abordagem epistemológica inovadora. Elisa Larkin Nascimento (org.). São Paulo: Selo Negro, 2009.

RIZK, Beatriz. El grupo de teatro yuyachkani e la errimisible presencia de la otredad. Buenos Aires \& Califórnia: Revista Argus-a. Vol 1, Ed. 1, p. 39-54, 2011.

SCHECHNER, Richard. Performance Studies: An introduction. London\&NY: Routledge, 2002.

TELLES, Narciso. Grupo Yuyachkani: pedagogia e memória. Urdimento, nำ17, 2011.

WACQUANT, Loïc. Que é gueto? Construindo um conceito sociológico. Revista de Sociologia. E Política. Curitiba: no 23, p. 155-164, nov. 2004.

Recebido em: 11/05/2015

Aprovado em: 02/07/2015 